\title{
Detrimental relevance of Helicobacter pylori infection with sarcopenia
}

\author{
Shou-En Wu $\mathbf{u}^{1,2,3}$ and Wei-Liang Chen ${ }^{2,3,4^{*}}$ (1)
}

\begin{abstract}
Background: Helicobacter pylori (H. pylori), Gram negative microaerophilic bacteria, is a well-known pathogen of many gastrointestinal diseases. But several emerging evidences suggest it role in numerous other extra-gastric diseases. The current study investigates the relationship between $\mathrm{H}$. pylori infection and sarcopenia, a clinical condition characterized by the loss of mass and function of skeletal muscle. A total of 3453 eligible participants from the Third National Health and Nutrition Examination Survey (NHANES III), the United States, were enrolled. Based on the serum laboratory results, subjects were categorized into three groups: normal (without evidence of any H. pylori infection), anti-H. pylori lgG positive [H. pylori (+)], and concurrent anti-H. pylori lgG and anti-cytotoxin-associated gene A IgG positive [CagA (+)]. Sarcopenia was determined as having a skeletal muscle index (SMI) value that is more than 1 standard deviation away from the mean value of sex-specific, healthy young adults between 20 and 39 years old. Risk of sarcopenia and its components are compared between subgroups.

Results: Odds ratios (OR) for confirmed diagnosis of sarcopenia were higher in $\mathrm{H}$. pylori $(+)(\mathrm{OR}=2.052,95 \% \mathrm{Cl}$ 1.697-2.481, $\mathrm{p}<0.001)$ and CagA $(+)(\mathrm{OR}=1.585,95 \% \mathrm{Cl} 1.278-1.965, \mathrm{p}<0.001)$ groups. Moreover, negative beta regression coefficient of SMI were shown in H. pylori $(+)(\beta:-0.023, p<0.001)$ and $\operatorname{CagA}(+)(\beta:-0.017, \mathrm{p}<0.001)$. Sub-analyses which categorized participants by gender revealed that absolute value of beta regression coefficient for SMI were higher in female in H. pylori ( + ) subgroup ( $\beta$ : -1.745 in male and -2.942 in female, $p$ were both $<0.001)$, and the CagA $(+)$ subgroup ( $\beta$ : -1.407 in male and -2.159 in female, $p$ were both $<0.001$ ).

Conclusions: Positive serum H. pylori infectious markers including anti-H. pylori antibody and CagA seropositivity are correlated with sarcopenia and low muscle quantity. Therefore, H. pylori eradication therapy may bring benefits to sarcopenia patients with concurrent active H. pylori infection.
\end{abstract}

Keywords: Helicobacter pylori, Sarcopenia, Muscle mass, Eradication therapy

\section{Background}

Helicobacter pylori (H. pylori) is a Gram-negative, helical-shaped bacterium that colonizes over $50 \%$ of the world's population [1]. Nevertheless, only $10-20 \%$ infected patients develop peptic ulcer disease, and 1-2\% develop gastric malignancy [2,3]. Aside from being a

\footnotetext{
*Correspondence: weiliang0508@gmail.com

${ }^{3}$ Division of Geriatric Medicine, Department of Family and Community Medicine, Tri-Service General Hospital; and School of Medicine, National Defense Medical Center, Number 325, Section 2, Chang-gong Rd, Nei-Hu District, Taipei 114, Taiwan, Republic of China

Full list of author information is available at the end of the article
}

renowned pathogen of gastrointestinal diseases, there is growing evidence of $H$. pylori's role in various extra-gastric diseases [4]. Literature has reported its relationship with neurological disorder (e.g., Alzheimer's diseases and multiple sclerosis) [5], dermatological diseases (e.g., rosacea) [6], hematologic diseases (e.g., iron deficiency anemia and primary immune thrombocytopenia) [7, 8], and so on. Manifestations in numerous sites of the body illustrate that $H$. pylori may induce not only local but systemic impacts that involve complex interactions [9].

Recently, societal aging has raised much health concern, including the increasing prevalence of sarcopenia, original author(s) and the source, provide a link to the Creative Commons licence, and indicate if changes were made. The images or other third party material in this article are included in the article's Creative Commons licence, unless indicated otherwise in a credit line to the material. If material is not included in the article's Creative Commons licence and your intended use is not permitted by statutory regulation or exceeds the permitted use, you will need to obtain permission directly from the copyright holder. To view a copy of this licence, visit http://creativecommons.org/licenses/by/4.0/. The Creative Commons Public Domain Dedication waiver (http://creativeco mmons.org/publicdomain/zero/1.0/) applies to the data made available in this article, unless otherwise stated in a credit line to the data. 
a muscle-related disorder that raises severe public health concern such as disability, falls, hospitalization, and mortality elderly population $[10,11]$. This arouses our interest of whether muscle, an extra-gastric organ, also possesses an association with $H$. pylori. A little research has been focused on the effect of $H$. pylori infection on muscle physiology [12], and no further evidence verifies the idea. Examining the association within may not only validate that $H$. pylori infection triggers systemic health effects, but also provides an extended understanding of the pathogenesis of sarcopenia that could possibly facilitate an alternative treatment strategy. The aim of the present study is exploring the relationship between serum $H$. pylori infectious markers and sarcopenia.

\section{Results}

\section{Demographic information of the study population}

In Table 1, participants were classified into three groups according to blood test results for $H$. pylori, namely normal, anti- $H$. pylori IgG positive, and concurrent anti- $H$. pylori and anti-cytotoxin-associated gene A (CagA) IgG positive. Most parameters including gait speed (time used for 8-feet walk), body mass index (BMI), C-reactive protein (CRP) levels or fasting glucose levels showed no statistical difference among groups. Few that showed difference were skeletal muscle index (SMI), race, diabetes mellitus, and sarcopenia. SMI were the lowest in the CagA (+) group $(41.82 \pm 10.98)$, and the highest in normal group $(44.69 \pm 9.83$,p value $<0.001)$. The proportion of non-Hispanic black and Mexican-American were higher in the CagA (+) (non-Hispanic black:29.9\%, Mexican-American:22.4\%) and H. pylori (+) (non-Hispanic black:22.0\%, Mexican-American:20.6\%) groups compared with the normal group (non-Hispanic black:16.6\%, Mexican-American:18.4\%) ( $<<0.001)$. The highest proportion of participants having diabetes mellitus appeared in the CagA $(+)$ group (17.2\%). Larger proportion of participants were diagnosed with sarcopenia in H. pylori $(+)$ $(10.9 \%)$ and CagA $(+)(10.4 \%)$ groups comparing to the normal group $(4.5 \%)(\mathrm{p}<0.001)$.

\section{Logistic regression models of association between serum anti-H. pylori IgG status, anti-CagA IgG status and sarcopenia}

To examine the association between serum $H$. pylori markers and sarcopenia, logistic regression models are

Table 1 Characteristics of study participants in normal, H. pylori $(+)$, and CagA (+) groups

\begin{tabular}{|c|c|c|c|c|}
\hline & Normal $^{\ddagger}(n=2805)$ & H. pylori $(+)^{\S}(n=514)$ & $\operatorname{CagA}(+)^{n}(n=134)$ & $P$ value \\
\hline \multicolumn{5}{|l|}{ Continuous valuest } \\
\hline Age (years) & $71.37 \pm 7.99$ & $71.74 \pm 8.07$ & $71.43 \pm 6.97$ & 0.770 \\
\hline BMI $\left(\mathrm{kg} / \mathrm{m}^{2}\right)$ & $27.24 \pm 5.10$ & $26.72 \pm 4.66$ & $27.22 \pm 5.13$ & 0.127 \\
\hline $\mathrm{SMI}\left(\mathrm{kg} / \mathrm{m}^{2}\right)$ & $44.69 \pm 9.83$ & $42.82 \pm 10.97$ & $41.82 \pm 10.98$ & $<0.001$ \\
\hline Time used for 8-feet walk(s) & $3.94 \pm 2.34$ & $3.80 \pm 1.48$ & $3.86 \pm 1.61$ & 0.542 \\
\hline Plasma CRP levels & $0.59 \pm 1.07$ & $0.51 \pm 0.73$ & $0.51 \pm 0.68$ & 0.156 \\
\hline Plasma glucose levels & $110.54 \pm 43.88$ & $107.61 \pm 44.24$ & $112.02 \pm 51.24$ & 0.464 \\
\hline \multicolumn{5}{|l|}{ Categorical values $^{\dagger}$} \\
\hline Male & $52.7 \%$ & $46.4 \%$ & $49.1 \%$ & 0.254 \\
\hline \multicolumn{5}{|l|}{ Race } \\
\hline Non-Hispanic white & $61.8 \%$ & $55.5 \%$ & $44.8 \%$ & $<0.001$ \\
\hline Non-Hispanic black & $16.6 \%$ & $22.0 \%$ & $29.9 \%$ & \\
\hline Mexican-American & $18.4 \%$ & $20.6 \%$ & $22.4 \%$ & \\
\hline Other & $3.2 \%$ & $1.8 \%$ & $2.9 \%$ & \\
\hline $\begin{array}{l}\text { Low muscle strength (difficulty lifting } 10 \\
\text { pounds) }\end{array}$ & $29.8 \%$ & $33.7 \%$ & $31.3 \%$ & 0.883 \\
\hline Smoker & $16.4 \%$ & $18.8 \%$ & $15.2 \%$ & 0.127 \\
\hline Doctor ever told to have arthritis & $44.5 \%$ & $42.9 \%$ & $43 \%$ & 0.704 \\
\hline Doctor ever told to have asthma & $6.3 \%$ & $6.7 \%$ & $5.6 \%$ & 0.069 \\
\hline Diabetes mellitus & $14.3 \%$ & $15.3 \%$ & $17.2 \%$ & 0.049 \\
\hline Sarcopenia & $126(4.5 \%)$ & $56(10.9 \%)$ & $14(10.4 \%)$ & $<0.001$ \\
\hline
\end{tabular}

\footnotetext{
${ }^{\dagger}$ Continuous values were expressed as mean and standard deviation; Categorical values in the categorical variables were expressed in number and percentage (\%)
}

${ }^{\ddagger}$ Normal: without evidence of positive anti-H. pylori lgG or anti-CagA lgG

${ }^{\S}$ H. pylori (+): positive anti-H. pylori lgG in serum samples

" CagA (+): concurrent positive anti-cytotoxin-associated gene A IgG and positive anti-H. pylori lgG in serum samples

BMI: Body mass index; SMI: Skeletal muscle index; CRP: C-reactive protein 
used to analyze the categorical variables, including confirmed diagnosis of sarcopenia (defined by low muscle mass in the present study), low gait speed and low muscle strength (Table 2). Odds ratios (OR) for confirmed diagnosis of sarcopenia were higher in $\mathrm{H}$. pylori (+) (OR 2.052, 95\% CI 1.697-2.481, p <0.001) and CagA $(+)$ $(\mathrm{OR}=1.585,95 \% \mathrm{CI} 1.278-1.965, \mathrm{p}<0.001)$ groups. ORs of low gait speed and low muscle strength didn't reveal statistical significance. The above results illustrated the higher probability of sarcopenia in $\mathrm{H}$. pylori $(+)$ and CagA (+) groups. The non-significant results in gait speed and muscle strength imply that muscle mass may be the first or decisive factor in certain scenarios.

\section{Linear regression models of association between serum anti-H. pylori IgG status, anti-CagA IgG status and sarcopenia}

Next, we examined the association between serum $H$. pylori markers and sarcopenia by calculating muscle mass, muscle strength and gait speed as continuous variables (Table 3). Linear regression models are used in current analysis. Beta regression coefficient of SMI in H. pylori $(+)(\beta:-0.023, \mathrm{p}<0.001)$ and CagA $(+)(\beta$ : $-0.017, \mathrm{p}<0.001)$ were of negative values. This explains the negative association between $H$. pylori infection and muscle mass, i.e., lower muscle mass in these two groups. On the other hand, results of gait speed did not reveal a similar trend with $\mathrm{p}$ values not reaching the statistical significance.

\section{Anti-H. pylori lgG status, anti-CagA IgG status and frequency of sarcopenia among males and females}

To examine whether gender difference exists in such relationship, subgroup analysis categorizing the participants by gender is performed (Tables 4 and 5 ). ORs of confirmed diagnosis of sarcopenia were similar in males and females in both $H$. pylori $(+)(\mathrm{OR}=2.164$ in male and 2.137 in female, $\mathrm{p}$ values were both $<0.001$ ) and $\mathrm{CagA}(+)(\mathrm{OR}=1.782$ in male and 1.650 in female, $\mathrm{p}$ values were $=0.010$ and 0.012 , respectively). ORs of low

Table 2 Odds ratios (OR) for sarcopenia and its components in normal, H. pylori (+), and CagA (+) groups

\begin{tabular}{|c|c|c|c|c|}
\hline Normal $^{\ddagger}$ & $\begin{array}{l}\text { Model } 1^{\dagger} \\
\text { Ref }\end{array}$ & $\begin{array}{l}\text { Model } 2 \\
\text { Ref }\end{array}$ & $\begin{array}{l}\text { Model } 3 \\
\text { Ref }\end{array}$ & $\begin{array}{l}\text { Model } 4 \\
\text { Ref }\end{array}$ \\
\hline \multicolumn{5}{|l|}{ Sarcopenia } \\
\hline \multicolumn{5}{|l|}{ H. pylori $(+)^{\S}$} \\
\hline OR & $1.832(1.578,2.128)$ & $1.860(1.577,2.194)$ & $2.035(1.685,2.459)$ & $2.052(1.697,2.481)$ \\
\hline P value & $<0.001$ & $<0.001$ & $<0.001$ & $<0.001$ \\
\hline \multicolumn{5}{|l|}{$\operatorname{CagA}(+)^{\natural}$} \\
\hline OR P value & $1.389(1.174,1.643)$ & $1.433(1.189,1.727)$ & $1.563(1.261,1.936)$ & $1.585(1.278,1.965)$ \\
\hline P value & $<0.001$ & $<0.001$ & $<0.001$ & $<0.001$ \\
\hline \multicolumn{5}{|c|}{ Low gait speed $(<0.8 \mathrm{~m} / \mathrm{s})$} \\
\hline \multicolumn{5}{|c|}{ H. pylori (+) } \\
\hline OR & $1.001(0.862,1.152)$ & $1.002(0.862,1.165)$ & $0.975(0.838,1.135)$ & $0.978(0.840,1.138)$ \\
\hline$P$ value & 0.966 & 0.980 & 0.748 & 0.774 \\
\hline \multicolumn{5}{|l|}{ CagA $(+)$} \\
\hline OR & $1.014(0.859,1.198)$ & $1.099(0.924,1.307)$ & $1.082(0.908,1.288)$ & $1.082(0.908,1.289)$ \\
\hline P value & 0.869 & 0.288 & 0.379 & 0.378 \\
\hline \multicolumn{5}{|c|}{ Difficulty lifting 10 pounds } \\
\hline \multicolumn{5}{|c|}{ H. pylori (+) } \\
\hline $\mathrm{OR}$ & $1.195(0.927,1.540)$ & $1.1840 .917,1.527)$ & $1.189(0.921,1.536)$ & $1.184(0.916,1.530)$ \\
\hline P value & 0.170 & 0.195 & 0.184 & 0.197 \\
\hline \multicolumn{5}{|l|}{ CagA (+) } \\
\hline OR & $1.021(0.756,1.379)$ & $1.012(0.746,1.373)$ & $1.010(0.744,1.370)$ & $0.998(0.735,1.355)$ \\
\hline$P$ value & 0.890 & 0.938 & 0.949 & 0.990 \\
\hline
\end{tabular}

${ }^{\dagger}$ Model $1=$ unadjusted

Model 2 =Adjusted for age, gender, race

Model 3 = Adjusted for age, gender, race, BMI, serum C-reactive protein, serum glucose

Model 4 = Adjusted for age, gender, race, BMI, serum C-reactive protein, serum glucose, smoking, arthritis, asthma, diabetes mellitus

${ }^{\ddagger}$ Normal: without evidence of positive anti-H. pylori lgG or anti-CagA IgG

$\S$ H. pylori (+): positive anti-H. pylori lgG in serum samples

" CagA (+): concurrent positive anti-cytotoxin-associated gene A IgG and positive anti-H. pylori lgG in serum samples 
Table 3 Association between components of sarcopenia and H. pylori markers in normal, H. pylori (+), and CagA (+) groups

\begin{tabular}{|c|c|c|c|c|}
\hline Normal $^{\ddagger}$ & $\begin{array}{l}\text { Model } 1^{\dagger} \\
\text { Ref }\end{array}$ & $\begin{array}{l}\text { Model } 2 \\
\text { Ref }\end{array}$ & $\begin{array}{l}\text { Model } 3 \\
\text { Ref }\end{array}$ & $\begin{array}{l}\text { Model } 4 \\
\text { Ref }\end{array}$ \\
\hline \multicolumn{5}{|c|}{ Skeletal muscle index $\left(\mathrm{kg} / \mathrm{m}^{2}\right)$} \\
\hline \multicolumn{5}{|c|}{ H. pylori $(+)^{\S}$} \\
\hline$\beta$ coefficient & $-0.015(-0.022,-0.009)$ & $-0.021(-0.027,-0.016)$ & $-0.023(-0.028,-0.018)$ & $-0.023(-0.029,-0.018)$ \\
\hline P value & $<0.001$ & $<0.001$ & $<0.001$ & $<0.001$ \\
\hline \multicolumn{5}{|l|}{$\operatorname{CagA}(+)^{\natural}$} \\
\hline$\beta$ coefficient & $-0.014(-0.022,-0.007)$ & $-0.016(-0.022,-0.009)$ & $-0.017(-0.023,-0.011)$ & $-0.017(-0.023,-0.011)$ \\
\hline P value & $<0.001$ & $<0.001$ & $<0.001$ & $<0.001$ \\
\hline \multicolumn{5}{|l|}{ Gait speed (m/s) } \\
\hline \multicolumn{5}{|l|}{ H.pylori (+) } \\
\hline$\beta$ coefficient & $0.019(-0.006,0.043)$ & $0.013(-0.010,0.036)$ & $0.009(-0.013,0.032)$ & $0.010(-0.013,0.033)$ \\
\hline$P$ value & 0.132 & 0.266 & 0.417 & 0.385 \\
\hline \multicolumn{5}{|l|}{$\operatorname{CagA}(+)$} \\
\hline$\beta$ coefficient & $0.014(-0.030,0.058)$ & $0.029(-0.013,0.071)$ & $0.027(-0.015,0.069)$ & $0.027(-0.015,0.069)$ \\
\hline Pvalue & 0.536 & 0.181 & 0.209 & 0.206 \\
\hline
\end{tabular}

${ }^{\dagger}$ Model $1=$ unadjusted

Model 2 = Adjusted for age, gender, race

Model 3 = Adjusted for age, gender, race, BMI, serum C-reactive protein, serum glucose

Model 4 = Adjusted for age, gender, race, BMI, serum C-reactive protein, serum glucose, smoking, arthritis, asthma, diabetes mellitus

${ }^{\ddagger}$ Normal: without evidence of positive anti-H. pylori lgG or anti-CagA lgG

${ }^{\S}$ H. pylori (+): positive anti-H. pylori lgG in serum samples

" CagA (+): concurrent positive anti-cytotoxin-associated gene A lgG and positive anti-H. pylori lgG in serum samples

gait speed and low muscle strength (difficulty lifting 10 pounds) didn't reveal statistical significance. As for SMI, absolute value of beta regression coefficient were higher in female in $H$. pylori $(+)$ subgroup $(\beta:-1.745$ in male and -2.942 in female, $\mathrm{p}$ were both $<0.001$ ), and the CagA $(+)$ subgroup $(\beta:-1.407$ in male and -2.159 in female, $\mathrm{p}$ were both $<0.001)$.

\section{Discussion}

The primary finding of this study is the positive association between sarcopenia and two $H$. pylori infection markers, serum anti-H. pylori IgG status and CagA seropositivity. Participants with positive anti- $H$. pylori IgG status and anti-CagA IgG status have higher risk of developing sarcopenia and low muscle mass (determined by SMI), whereas the other two indications of sarcopenia (i.e., low muscle strength and low physical performance) didn't show significant relationship. Previous research has not put much attention on the association between H. pylori infection and sarcopenia. The merely one that we came across was a study performed in Seoul, Korea which revealed elderly women receiving $H$. pylori eradication therapy had decreased risk of low skeletal muscle mass [12]. However, it was limited to female and did not further evaluate the status of muscle function. To the best of our knowledge, we are the first to propose the link between $H$. pylori infection and sarcopenia.

There are three essential findings in our study that are worth discussing. First, we demonstrated that not only anti-H. pylori IgG status but also CagA seropositivity relates to sarcopenia. Anti-CagA IgG status may not be considered as a marker for infection as cagA-negative strains also exist. However, CagA is one of the virulence factors that strongly links to more severe conditions like peptic ulcer and gastric cancer [13]. The CagA protein is injected into the host cell by a type 4 secretion system. Inside the cell, the protein activates a cascade of downstream events resulting in induce altered cell morphology, cell proliferation and damaged cell junction. Clinicians may consider shortening the screening intervals for sarcopenia in patients who are concurrent seropositive for anti-H. pylori and anti-CagA $(+)$ antibodies. Second, low muscle mass is the only component of sarcopenia that showed correlation with $H$. pylori infection. This may be due to the direct influence of $H$. pylori infection on muscle quality and quantity (possible mechanisms are described in the following section). Nevertheless, if we conduct a longitudinal study that tracks patients over a period of time, the impact on muscle function may appear. Third, the absolute value of beta coefficient was higher in female in H. pylori $(+)$ and 
Table 4 Odds ratios (OR) for sarcopenia and its components in normal, H. pylori (+), and CagA (+) groups categorized by gender

\begin{tabular}{|c|c|c|c|c|c|c|}
\hline & \multicolumn{3}{|c|}{ Male $(n=1765)$} & \multicolumn{3}{|c|}{ Female $(n=1688)$} \\
\hline & $\begin{array}{l}\text { Normal } \\
(n=1455)\end{array}$ & H. pylori $(+)(n=233)$ & CagA $(+)(n=77)$ & $\begin{array}{l}\text { Normal } \\
(n=1350)\end{array}$ & H. pylori $(+)(n=281)$ & $\operatorname{CagA}(+)(n=57)$ \\
\hline \multicolumn{7}{|l|}{ Sarcopenia } \\
\hline \multicolumn{7}{|l|}{ Model 1} \\
\hline OR & Ref & $2.132(1.441,3.153)$ & $1.801(1.171,2.770)$ & Ref & $2.127(1.508,3.002)$ & $1.678(1.143,2.463)$ \\
\hline$P$ value & Ref & $<0.001$ & 0.007 & Ref & $<0.001$ & 0.008 \\
\hline \multicolumn{7}{|l|}{ Model 2} \\
\hline OR & Ref & $2.085(1.408,3.087)$ & $1.745(1.130,2.695)$ & Ref & $2.119(1.501,2.992)$ & $1.652(1.124,2.430)$ \\
\hline P value & Ref & $<0.001$ & 0.012 & Ref & $<0.001$ & 0.011 \\
\hline \multicolumn{7}{|l|}{ Model 3} \\
\hline OR & Ref & $2.161(1.456,3.208)$ & $1.776(1.148,2.748)$ & Ref & $2.155(1.525,3.047)$ & $1.679(1.141,2.470)$ \\
\hline$P$ value & Ref & $<0.001$ & 0.010 & Ref & $<0.001$ & 0.009 \\
\hline \multicolumn{7}{|l|}{ Model 4} \\
\hline OR & Ref & $2.164(1.457,3.214)$ & $1.782(1.151,2.759)$ & Ref & $2.137(1.509,3.026)$ & $1.650(1.118,2.436)$ \\
\hline$P$ value & Ref & $<0.001$ & 0.010 & Ref & $<0.001$ & 0.012 \\
\hline \multicolumn{7}{|c|}{ Low gait speed $(<0.8 \mathrm{~m} / \mathrm{s})$} \\
\hline \multicolumn{7}{|c|}{ Model 1} \\
\hline OR & Ref & $1.137(0.843,1.534)$ & $0.923(0.571,1.493)$ & Ref & $1.291(0.991,1.682)$ & $1.597(0.909,2.807)$ \\
\hline P value & Ref & 0.400 & 0.744 & Ref & 0.058 & 0.103 \\
\hline \multicolumn{7}{|l|}{ Model 2} \\
\hline OR & Ref & $1.197(0.877,1.633)$ & $0.794(0.482,1.308)$ & Ref & $1.301(0.990, .710)$ & $1.509(0.847,2.690)$ \\
\hline P value & Ref & 0.256 & 0.365 & Ref & 0.059 & 0.163 \\
\hline \multicolumn{7}{|l|}{ Model 3} \\
\hline OR & Ref & $1.288(0.940,1.765)$ & $0.794(0.480,1.313)$ & Ref & $1.335(1.014,1.757)$ & $1.552(0.838,2.773)$ \\
\hline P value & Ref & 0.115 & 0.368 & Ref & 0.039 & 0.138 \\
\hline \multicolumn{7}{|l|}{ Model 4} \\
\hline OR & Ref & $1.287(0.938,1.765)$ & $0.800(0.483,1.326)$ & Ref & $1.336(1.014,1.759)$ & $1.558(0.872,2.783)$ \\
\hline P value & Ref & 0.118 & 0.388 & Ref & 0.039 & 0.135 \\
\hline \multicolumn{7}{|c|}{ Low muscle strength (difficulty lifting 10 pounds) } \\
\hline \multicolumn{7}{|c|}{ Model 1} \\
\hline OR & Ref & $1.246(0.761,2.042)$ & $0.787(0.308,2.012)$ & Ref & $1.373(0.867,2.174)$ & $1.264(0.519,3.080)$ \\
\hline$P$ value & Ref & 0.382 & 0.617 & Ref & 0.176 & 0.606 \\
\hline \multicolumn{7}{|l|}{ Model 2} \\
\hline OR & Ref & $1.241(0.757,2.034)$ & $0.796(0.311,2.039)$ & Ref & $1.382(0.872,2.191)$ & $1.240(0.506,3.038)$ \\
\hline P value & Ref & 0.392 & 0.635 & Ref & 0.169 & 0.638 \\
\hline \multicolumn{7}{|l|}{ Model 3} \\
\hline OR & Ref & $1.250(0.761,2.051)$ & $0.782(0.304,2.013)$ & Ref & $1.385(0.872,2.201)$ & $1.227(0.500,3.009)$ \\
\hline P value & Ref & 0.378 & 0.610 & Ref & 0.167 & 0.655 \\
\hline \multicolumn{7}{|l|}{ Model 4} \\
\hline OR & Ref & $1.279(0.776,2.108)$ & $0.791(0.306,2.044)$ & Ref & $1.344(0.844,2.140)$ & $1.153(0.467,2.850)$ \\
\hline Pvalue & Ref & 0.334 & 0.629 & Ref & 0.213 & 0.757 \\
\hline
\end{tabular}

${ }^{\dagger}$ Model $1=$ unadjusted

Model 2 = Adjusted for age, race

Model 3 =Adjusted for age, race, BMI, serum C-reactive protein, serum glucose

Model 4 =Adjusted for age, race, BMI, serum C-reactive protein, serum glucose, smoking, arthritis, asthma, diabetes mellitus

CagA (+) subgroup, illustrating the greater decrease in SMI in female patients of $H$. pylori infection. This is quite interesting finding as several previous studies mostly revealed that $H$. pylori infected males have higher risk of developing gastric-related diseases including chronic gastritis and gastric cancer [14, 15]. Our finding implied there may be a different trend of gender predominance in sarcopenia, which is a muscle disease primarily found 
Table 5 Association between SMI and H. pylori markers in normal, H. pylori (+), and CagA (+) groups categorized by gender

\begin{tabular}{|c|c|c|c|c|c|c|}
\hline & \multicolumn{3}{|c|}{ Male $(n=1765)$} & \multicolumn{3}{|c|}{ Female $(n=1661)$} \\
\hline & $\begin{array}{l}\text { Normal } \\
(n=1455)\end{array}$ & H. pylori $(+)(n=233)$ & $\operatorname{CagA}(+)(n=77)$ & $\begin{array}{l}\text { Normal } \\
(n=1323)\end{array}$ & H. pylori $(+)(n=281)$ & $\operatorname{CagA}(+)(n=57)$ \\
\hline \multicolumn{7}{|c|}{ Skeletal muscle index(SMI) } \\
\hline \multicolumn{7}{|c|}{ Model 1} \\
\hline$\beta$ coefficient & Ref & $\begin{array}{l}-1.525(-2.392 \\
-0.658)\end{array}$ & $\begin{array}{l}-1.563(-2.546 \\
-0.581)\end{array}$ & Ref & $\begin{array}{l}-2.369(-3.323 \\
-1.414)\end{array}$ & $-1.476(-2.591,-0.361)$ \\
\hline P value & Ref & 0.001 & 0.002 & Ref & $<0.001$ & 0.010 \\
\hline \multicolumn{7}{|l|}{ Model 2} \\
\hline$\beta$ coefficient & Ref & $\begin{array}{l}-1.266(-2.101 \\
-0.432)\end{array}$ & $\begin{array}{l}-1.321(-2.271 \\
-0.371)\end{array}$ & Ref & $\begin{array}{l}-2.601(-3.539 \\
-1.663)\end{array}$ & $-1.676(-2.776,-0.576)$ \\
\hline P value & Ref & 0.003 & 0.006 & Ref & $<0.001$ & 0.003 \\
\hline \multicolumn{7}{|l|}{ Model 3} \\
\hline$\beta$ coefficient & Ref & $\begin{array}{l}-1.733(-2.406 \\
-1.060)\end{array}$ & $\begin{array}{l}-1.390(-2.158 \\
-0.622)\end{array}$ & Ref & $\begin{array}{l}-2.926(-3.747 \\
-2.106)\end{array}$ & $-2.144(-3.107,-1.181)$ \\
\hline P value & Ref & $<0.001$ & $<0.001$ & Ref & $<0.001$ & $<0.001$ \\
\hline \multicolumn{7}{|l|}{ Model 4} \\
\hline$\beta$ coefficient & Ref & $\begin{array}{l}-1.740(-2.413 \\
-1.067)\end{array}$ & $\begin{array}{l}-1.407(-2.175 \\
-0.640)\end{array}$ & Ref & $\begin{array}{l}-2.942(-3.763 \\
-2.122)\end{array}$ & $-2.159(-3.123,-1.194)$ \\
\hline P value & Ref & $<0.001$ & $<0.001$ & Ref & $<0.001$ & $<0.001$ \\
\hline
\end{tabular}

${ }^{\dagger}$ Model 1 = unadjusted

Model 2 = Adjusted for age, race

Model 3 = Adjusted for age, race, BMI, serum C-reactive protein, serum glucose

Model 4 =Adjusted for age, race, BMI, serum C-reactive protein, serum glucose, smoking, arthritis, asthma, diabetes mellitus

in elderly population. Estrogen may be the key character here. Previous literature has illustrated the protective role of estrogen against $H$. pylori infection [16, 17], but the average age of our participants (71.37 \pm 7.99 years old), were old enough to be in postmenopausal stage, who have lost the privilege of hormone protection. This might lead to a more vulnerable status in elderly female, which turned out to have a higher degree of muscle decline after H. pylori infection.

Possible mechanisms underlying the interrelation are as follows. First, H. pylori infection results in dysbiosis of gut microbiome, and these alterations may further cause sarcopenia through a gut-muscle axis that was mentioned in previous articles [18-20]. Microbiota in the gastric system maintains a delicate balance in immunity and health by producing multiple mediators that influences not only the gastro-intestinal tract but distal organs. Muscle, inevitably, is one of the victims if dysregulation occurs. Secondly, H. pylori induces fluctuations of hormones that regulates energy homeostasis including ghrelin and leptin [21-23]. Ghrelin, mainly produced by gastric endocrine cells, stimulates appetite and the release of growth hormone. Evidence showed decreased ghrelin levels in sarcopenia patients [24], while another study proved improvement of physical decline through ghrelin administration [25]. On the other hand, leptin is the product of adipocytes and gastric endocrine cells, and modulates fat storage and appetite control. Studies have discussed changes of leptin levels in sarcopenia patients, and recognized its role in aging muscle [26]. Collectively, ghrelin and leptin may bridge $H$. pylori and sarcopenia altogether. Third, H. pylori infection leads to inflammatory response through cytokines including interleukin-1,6,12 (IL-1, IL-6, IL-12), tumor necrosis factor- $\alpha($ TNF- $\alpha)$, and interferon- $\gamma$ (IFN- $\gamma$ ) [27]. The initial local inflammation could spread as these cytokines circulates in the bloodstream. Chronic inflammatory condition brings negative effects to muscle mass and strength, ultimately giving rise to the occurrence of sarcopenia [28]. Last but not least, H. pylori infection decreases absorption of vital nutrients, which in turn causes growth retard in childhood, and unsurprisingly, sarcopenia in the elderly [29]. The above speculations are yet to be verified, but fairly reasonable to explain the association between $\mathrm{H}$. pylori infection and sarcopenia.

The importance of certain investigation is the growing evidence of extra-gastric diseases caused by $H$. pylori [4]. Aside from the well-known determinant pathogen of chronic gastritis, peptic ulcer, gastric adenocarcinoma, and gastric mucosa associated lymphoid tissue (MALT) lymphoma [30, 31], recent studies imply that H. pylori may not just pose threat to the body locally 
but rather have a great impact systemically. As a potential influencing factor in neurological, dermatological, and hematologic diseases $[5,7,8,32]$, the mechanism of H. pylori pathogenicity is apparently multifactorial and complicated. Fortunately, current guidelines of treatment regimens can achieve almost $90 \%$ eradication rate [33]. In other words, the prognosis of diseases that were discovered to have association with $H$. pylori infection is promising. The target of our study, sarcopenia, is a disorder that raises public health concern such as disability, falls, hospitalization, and mortality [10, 11], but still awaits effective therapeutic strategies due to multifactorial etiology. According to the findings of our study, we propose that anti- $H$. pylori IgG seropositive patients should receive further stool antigen test, rapid urease test or urea breath test to confirm if there is active infection. Subsequently, patients with concurrent active $H$. pylori infection and sarcopenia should start $H$. pylori eradication therapy with no delay to avoid deterioration of muscle mass.

There are limitations of this study that should be mentioned. First, National Health and Nutrition Examination Survey (NHANES) itself is a cross-sectional study collecting information at a specific point of time, which weakens the causal inference made from this data. In addition, NHANES only collects data from noninstitutionalized US population, and thus the application in other countries or regions need further studies. Second, we utilized blood test results for detecting $H$. pylori infection because other exam methods were not available from NHANES. Other non-invasive tests, urea breath test and stool antigen test, are useful as they can distinguish active infection from past exposure [34]. However, serological tests are proved to be as accurate in untreated patients [35]. As our goal is investigating the relationship between $H$. pylori infection and sarcopenia, we believe adopting both past and current infection of $H$. pylori can still reflect real condition. Third, CagA status are mostly detected by polymerase chain reaction (PCR) in fecal and biopsy samples $[36,37]$. Though serological detection is revealed to be sensitive [38], but it is still a relatively indirect mean comparing to PCR.

\section{Conclusions}

Serum $H$. pylori infection markers including anti- $H$. pylori antibody and CagA seropositivity are associated with sarcopenia and low muscle quantity. Once an active $H$. pylori infection is confirmed, patients who are at high risk of sarcopenia may consider receiving $H$. pylori eradication therapy concerning the dual benefit of treating the bacterial infection as well as alleviating the deterioration of muscle mass. Further studies are warranted to verify the application in different races and the possible mechanisms underlying this relationship.

\section{Methods}

Study population and data collection

Data were obtained from the Third NHANES (NHANES III), which enrolled 39,695 nationwide samples of US population from 1988 to 1994 . NHANES is one of the data collection systems of the National Center for Health Statistics (NCHS), a part of the Centers for Disease Control and Prevention (CDC). Different from recent data which is collected and released every 2 years, this 6-year sample was categorized into three released files, containing augmented and surplus data of environmental exposure and sera laboratory components in later years. All study protocols were approved by the Institutional Review Board of CDC, and written informed consent was obtained from each participant. According to our study design, we first included those $\geq 60$ years old $(n=5476)$, as sarcopenia is an age-related disease characterized by decline in muscle mass, strength and function [39]. Then, we excluded those with missing related information of serum $H$. pylori antibody, serum CagA seropositivity, skeletal muscle mass index, and gait speed. After proper selection, 3453 participants were eligible for further analyses.

For determining an adequate sample size to ensure statistical power, we admit a degree of error in the estimate of $5 \%$ and a confidence interval of $95 \%$. Based on previous studies, the prevalence of sarcopenia in US population ranges from 45 to $59 \%$. It was calculated as necessary to recruit a minimum number of 371 to 379 subjects to obtain an acceptable estimate ( $80 \%$ power). Thus, in the current study with a total of 3453 participants allows us to make a statistically reliable sample of the prevalence of sarcopenia.

\section{Definition of sarcopenia and anthropometric measurements}

Muscle mass was measured using bioelectrical impedance analysis(BIA) in NHANES III, which is considered an applicable alternative to whole body by dual-energy X-ray absorptiometry (DXA) by international guidelines [40, 41]. The instrument was Valhalla 1990B Bio-Resistance Body Composition Analyzer (Valhalla Scientific, San Diego, CA, USA). We adopted the analytical equation developed by Janssen et al. [42]: skeletal muscle mass $(\mathrm{kg})=\left[\right.$ height $^{2}$ (in $\left.\mathrm{cm}\right) /$ BIA resistance (in ohms, $\Omega) \times 0.401)+($ gender $\times 3.825)+($ age $\quad$ in years $) \times-0.071)]+5.102$. SMI was further calculated by dividing the skeletal muscle mass above (in $\mathrm{kg}$ ) by height squared $\left(\mathrm{m}^{2}\right)$. Sarcopenia was defined as having a SMI which is more than one standard deviation (SD) away 
from sex-specific, healthy population between the ages of 20-39, following similar studies [43, 44]. In our study, the cutoff values of sarcopenia were $<10.76 \mathrm{~kg} / \mathrm{m}^{2}$ in men and $<6.76 \mathrm{~kg} / \mathrm{m}^{2}$ in women.

Other components that evaluate impaired physical performance of sarcopenia are as follows. The muscle strength was determined by assessing the ability of the participant to lift or carry 10-pound weight and the degree of muscle strength was graded to no difficulty, some difficulty, much difficulty or unable. Participants answering' much difficulty' and 'unable' were classified into the low muscle strength group. Gait speed is calculated by the time used for completing 8-feet walk which is carried out in the Mobile Examination Center (MEC).

\section{Determination of $H$. pylori infection}

The status of serum anti-H. pylori IgG antibody and serum anti-CagA IgG antibody were obtained from the NHANES III surplus documents. Antibodies to H. pylori were assessed using ELISA with Pyloristat kit (Whittaker Bioproducts, Walkersville, Maryland, USA); IgG antibodies to CagA were measured using an optimal ELISA assay using recombinant CagA for the detection of antiCagA antibody developed by Vanderbilt University [45]. Detailed methodology followed protocols developed by Blaser et al. in 1980s [46].

\section{Covariates}

The details of self-reported demographic information are listed in the following. The BMI was calculated by weight in kilograms divided by height in meters squared $\left(\mathrm{kg} / \mathrm{m}^{2}\right)$. Gait speed $(\mathrm{m} / \mathrm{s})$ was calculated by dividing the distance of 8 -feet walk $(2.44 \mathrm{~m})$ by the time (second) used for it. As for serum laboratory results, plasma glucose was measured with a modified hexokinase enzymatic method, and plasma C-reactive protein levels with an automated Behring Nephelometer Analyzer System (Behring Diagnostics, Inc, Somerville, NJ) [47]. The study population were classified based on their race into four categories, non-Hispanic white, non-Hispanic black, Mexican-American, and others (including multi-racial). Positive smoking history was recognized by responding yes to the question" have you ever smoked at least 20 cigarettes in your entire life?" Medical conditions including arthritis, asthma or diabetes mellitus were identified by the fact patients had been diagnosed with or told with the above diseases. All information was collected following standardized protocols formulated on the CDC reference instruments and manuals.

\section{Study design and statistical analysis}

Participants were classified into three groups: normal (without evidence of any $H$. pylori infection), anti$H$. pylori IgG positive [presented in the context as $H$. pylori (+)], and concurrent anti-H. pylori IgG and anticytotoxin-associated gene A IgG positive [presented in

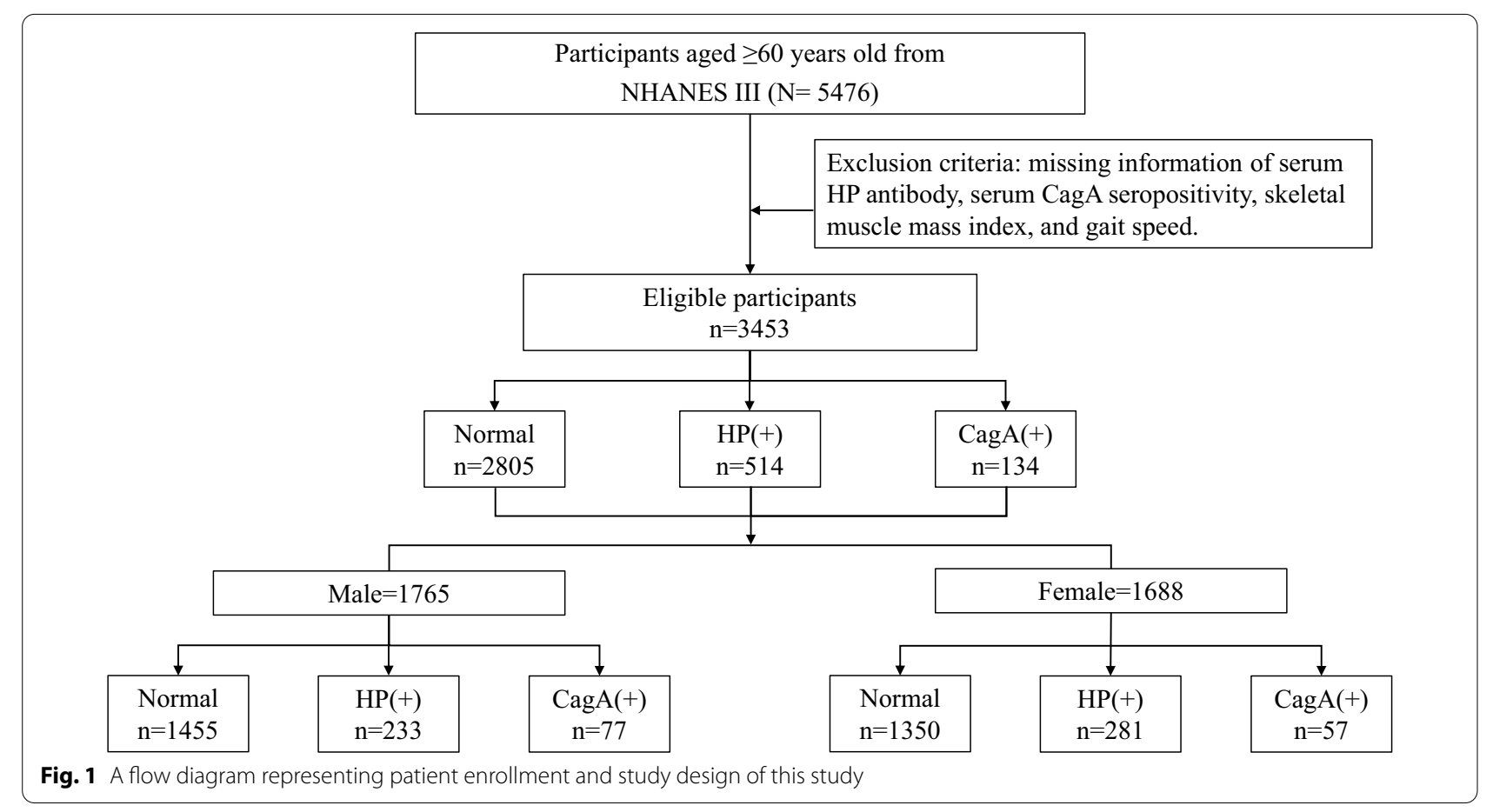


the context as CagA $(+)]$. The analytic software used here was SPSS (IBM Corp. Released 2013. IBM SPSS Statistics for Windows, Version 22.0. Armonk, NY: IBM Corp.). Quantitative parameters were indicated as means and SDs, whereas quantitative parameters were indicated as number and percentage (\%). Demographic characteristics were compared by an independent t-test; a Student's t-test was used for continuous variables and Chi-square test for categorical variables. Logistic regression was used to predict risk of each subgroup toward qualitative variables such as low gait speed, diagnosis of sarcopenia and having difficulty lifting heavy objects; Linear regression was used to predict risk toward quantitative variables like skeletal muscle index (SMI) and gait speed. Four expanded models were offered for adequate correction, with Model 1 being the unadjusted one, and Model 2,3,4 being adjusted ones with different confounding variables. All $\mathrm{p}$ values $<0.05$ were considered statistically significant. Sub-analyses of separate gender were also performed. A study flow diagram is presented in Fig. 1.

\begin{abstract}
Abbreviations
H. pylori: Helicobacter pylori; CagA: Cytotoxin-associated gene A; NHANES III: Third National Health and Nutrition Examination Survey; NCHS: National Center for Health Statistics; CDC: Centers for Disease Control and Prevention; MEC: Mobile Examination Center; BIA: Bioelectrical impedance analysis; DXA: Dual-energy X-ray absorptiometry; SMI: Skeletal muscle index; SD: Standard deviation; BMI: Body mass index; OR: Odds ratio; IL: Interleukin; TNF: Tumor necrosis factor; IF: Interferon; MALT: Mucosa associated lymphoid tissue; PCR: Polymerase chain reaction.
\end{abstract}

\section{Acknowledgements}

Not applicable.

\section{Authors' contributions}

SEW: Roles/Writing—original draft; formal analysis; visualization. W-LC: Conceptualization; data curation; investigation; methodology; project administration; resources; software; supervision; validation; writing—-review \& editing. All authors read and approved the final manuscript.

\section{Funding}

This research did not receive any specific grant from funding agencies in the public, commercial, or not-for-profit sectors

\section{Availability of data and materials}

The datasets generated and/or analyzed during the current study are publicly available from the NHANES website. (https://wwwn.cdc.gov/nchs/nhanes/ nhanes3/default.aspx).

\section{Declarations}

Ethics approval and consent to participate

National Health and Nutrition Examination Survey (NHANES) is a publicly available data set and all participants in NHANES provide written informed consent, consistent with approval from the National Center for Health Statistics Research Ethics Review Board (NCHS ERB).

\section{Consent for publication}

Not applicable.

\section{Competing interests}

The authors declare that they have no competing interests.

\section{Author details}

${ }^{1}$ Department of Dermatology, Tri-Service General Hospital; and School of Medicine, National Defense Medical Center, Taipei, Taiwan, Republic of China. ${ }^{2}$ Division of Family Medicine, Department of Family and Community Medicine, Tri-Service General Hospital; and School of Medicine, National Defense Medical Center, Taipei, Taiwan, Republic of China. ${ }^{3}$ Division of Geriatric Medicine, Department of Family and Community Medicine, Tri-Service General Hospital; and School of Medicine, National Defense Medical Center, Number 325, Section 2, Chang-gong Rd, Nei-Hu District, Taipei 114, Taiwan, Republic of China. ${ }^{4}$ Department of Biochemistry, National Defense Medical Center, Taipei, Taiwan, Republic of China.

Received: 27 May 2021 Accepted: 9 November 2021

Published online: 15 November 2021

\section{References}

1. Salih BA. Helicobacter pylori infection in developing countries: the burden for how long? Saudi J Gastroenterol. 2009;15(3):201.

2. Kusters JG, Van Vliet AH, Kuipers EJ. Pathogenesis of Helicobacter pylori infection. Clin Microbiol Rev. 2006;19(3):449-90.

3. Ernst PB, Gold BD. The disease spectrum of Helicobacter pylori: the immunopathogenesis of gastroduodenal ulcer and gastric cancer. Annu Rev Microbiol. 2000;54(1):615-40.

4. Franceschi F, Gasbarrini A, Polyzos SA, Kountouras J. Extragastric diseases and Helicobacter pylori. Best Pract Res Clin Gastroenterol. 2015;20:40-6.

5. Kountouras J, Tsolaki M, Gavalas E, Boziki M, Zavos C, Karatzoglou P, et al. Relationship between Helicobacter pylori infection and Alzheimer disease. Neurology. 2006;66(6):938-40.

6. Yang X. Relationship between Helicobacter pylori and Rosacea: review and discussion. BMC Infect Dis. 2018;18(1):318.

7. Choe YH, Kim SK, Son BK, Lee DH, Hong YC, Pai SH. Randomized placebo-controlled trial of Helicobacter pylori eradication for irondeficiency anemia in preadolescent children and adolescents. Helicobacter. 1999:4(2):135-9.

8. Franchini M, Veneri DJP. Helicobacter pylori-associated immune thrombocytopenia. Platelets. 2006;17(2):71-7.

9. Bravo D, Hoare A, Soto C, Valenzuela MA, Quest AF. Helicobacter pylori in human health and disease: mechanisms for local gastric and systemic effects. World J Gastroenterol. 2018;24(28):3071.

10. Beaudart C, Rizzoli R, Bruyère O, Reginster J-Y, Biver E. Sarcopenia: burden and challenges for public health. Arch Public Health. 2014;72(1):45.

11. Janssen I, Shepard DS, Katzmarzyk PT, Roubenoff RJ. The healthcare costs of sarcopenia in the United States. J Am Geriatr Soc. 2004;52(1):80-5.

12. Baeg MK, Choi M, Ko S-H, Lim C-H, Kim JS, Cho YK, et al. Elderly women who received Helicobacter pylori-eradicating therapy have reduced risk of low skeletal muscle mass. Clin Intervent Aging. 2015;10:1771.

13. Jones KR, Whitmire JM, Merrell DS. A tale of two toxins: Helicobacter pylori CagA and VacA modulate host pathways that impact disease. Front Microbiol. 2010;1:115.

14. Fox JG, Rogers AB, Ihrig M, Taylor NS, Whary MT, Dockray G, et al. Helicobacter pylori-associated gastric cancer in INS-GAS mice is gender specific. Can Res. 2003;63(5):942-50.

15. Kang GH, Lee HJ, Hwang KS, Lee S, Kim J-H, Kim JSJ. Aberrant CpG island hypermethylation of chronic gastritis, in relation to aging, gender, intestinal metaplasia, and chronic inflammation. Am J Pathol. 2003;163(4):1551-6.

16. Ohtani M, Ge Z, García A, Rogers AB, Muthupalani S, Taylor NS, et al. $17 \beta$-Estradiol suppresses Helicobacter pylori-induced gastric pathology in male hypergastrinemic INS-GAS mice. Carcinogenesis. 2011;32(8):1244-50.

17. Ohtani M, García A, Rogers AB, Ge Z, Taylor NS, Xu S, et al. Protective role of $17 \beta$-estradiol against the development of Helicobacter pylori-induced gastric cancer in INS-GAS mice. Carcinogenesis. 2007;28(12):2597-604. 
18. Ticinesi A, Lauretani F, Milani C, Nouvenne A, Tana C, Del Rio D, et al. Aging gut microbiota at the cross-road between nutrition, physical frailty, and sarcopenia: is there a gut-muscle axis? Nutrients. 2017;9(12):1303.

19. Ticinesi A, Tana C, Nouvenne A, Meschi TJ. Human Gut Microbiome: the Hypothesis of a Gut-Muscle Axis in the Elderly. German Journal of Sports Medicine/Deutsche Zeitschrift fur Sportmedizin. 2018;69(12).

20. Picca A, Fanelli F, Calvani R, Mulè G, Pesce V, Sisto A, et al. Gut dysbiosis and muscle aging: searching for novel targets against sarcopenia. Mediat Inflamm. 2018:2018:7026198.

21. Jeffery PL, McGuckin MA, Linden SK. Endocrine impact of Helicobacter pylori: focus on ghrelin and ghrelin o-acyltransferase. World J Gastroenterol. 2011;17(10):1249.

22. Roper J, Francois F, Shue PL, Mourad MS, Pei Z, Olivares de Perez AZ, et al. Leptin and ghrelin in relation to Helicobacter pylori status in adult males. J Clin Endocrinol Metab. 2008;93(6):2350-7.

23. Azuma T, Suto H, Ito Y, Ohtani M, Dojo M, Kuriyama M, et al. Gastric leptin and Helicobacter pylori infection. Gut. 2001;49(3):324-9.

24. Serra-Prat M, Papiol M, Monteis R, Palomera E, Cabré M. Relationship between plasma ghrelin levels and sarcopenia in elderly subjects: a crosssectional study. J Nutr Health Aging. 2015;19(6):669-72.

25. Tamaki M, Miyashita K, Hagiwara A, Wakino S, Inoue H, Fujii K, et al. Ghrelin treatment improves physical decline in sarcopenia model mice through muscular enhancement and mitochondrial activation. Endocr J. 2017;64:S47-51.

26. Kohara K, Ochi M, Tabara Y, Nagai T, Igase M, Miki T. Leptin in sarcopenic visceral obesity: possible link between adipocytes and myocytes. PloS ONE. 2011:6(9):e24633.

27. Figueiredo CA, Marques CR, dos Santos CR, da Silva HBF, Alcantara-Neves NM. Cytokines, cytokine gene polymorphisms and Helicobacter pylori infection: friend or foe? World J Gastroenterol. 2014;20(18):5235.

28. Dalle $\mathrm{S}$, Rossmeislova $\mathrm{L}$, Koppo K. The role of inflammation in age-related sarcopenia. Front Physiol. 2017;8:1045.

29. Franceschi F, Annalisa T, Di Rienzo TD, laniro G, Franco S, Viviana G, et al. Role of Helicobacter pylori infection on nutrition and metabolism. World J Gastroenterol. 2014;20(36):12809.

30. Parsonnet J, Hansen S, Rodriguez L, Gelb AB, Warnke RA, Jellum E, et al. Helicobacter pylori infection and gastric lymphoma. N Engl J Med. 1994:330(18):1267-71

31. Parsonnet J, Friedman GD, Vandersteen DP, Chang Y, Vogelman JH, Orentreich $\mathrm{N}$, et al. Helicobacter pylori infection and the risk of gastric carcinoma. N Engl J Med. 1991;325(16):1127-31.

32. Li W, Minohara M, Su JJ, Matsuoka T, Osoegawa M, Ishizu T, et al. Helicobacter pylori infection is a potential protective factor against conventional multiple sclerosis in the Japanese population. J Neuroimmunol. 2007;184(1-2):227-31.

33. Chey WD, Leontiadis Gl, Howden CW, Moss SF. ACG clinical guideline: treatment of Helicobacter pylori infection. Am J Gastroenterol. 2017;112(2):212-39.
34. Ricci C, Holton J, Vaira DJBP, Gastroenterology RC. Diagnosis of Helicobacter pylori: invasive and non-invasive tests. Best Pract Res Clin Gastroenterol. 2007:21(2):299-313.

35. Cutler AF, Havstad S, Ma CK, Blaser MJ, Perez-Perez GI, Schubert TTJG. Accuracy of invasive and noninvasive tests to diagnose Helicobacter pylori infection. Gastroenterology. 1995;109(1):136-41.

36. Lage AP, Godfroid E, Fauconnier A, Burette A, Butzler J-P, Bollen A, et al. Diagnosis of Helicobacter pylori infection by PCR: comparison with other invasive techniques and detection of cagA gene in gastric biopsy specimens. J Clin Microbiol. 1995;33(10):2752-6.

37. Russo F, Notarnicola M, Di Matteo G, Leoci C, Caruso ML, Pirrelli M, et al. Detection of Helicobacter pylori cagA gene by polymerase chain reaction in faecal samples. Eur J Gastroenterol Hepatol. 1999;11(3):251-6.

38. Cover TL, Glupczynski Y, Lage AP, Burette A, Tummuru M, Perez-Perez $\mathrm{Gl}$, et al. Serologic detection of infection with cagA+ Helicobacter pylori strains. J Clin Microbiol. 1995;33(6):1496-500.

39. Waters DL, Baumgartner RN, Garry PJ. Sarcopenia: current perspectives. J Nutr Health Aging. 2000;4(3):133-9.

40. Cruz-Jentoft AJ, Bahat G, Bauer J, Boirie Y, Bruyère O, Cederholm T, et al. Sarcopenia: revised European consensus on definition and diagnosis. Age Ageing. 2019;48(1):16-31.

41. Chen L-K, Woo J, Assantachai P, Auyeung T-W, Chou M-Y, lijima K, et al. Asian Working Group for Sarcopenia: 2019 consensus update on sarcopenia diagnosis and treatment. J Am Med Direct Assoc. 2020;21(3):300-7.

42. Janssen I, Heymsfield SB, Baumgartner RN, Ross RJ. Estimation of skeletal muscle mass by bioelectrical impedance analysis. J Appl Physiol. 2000;89(2):465-71.

43. Janssen I, Heymsfield SB, Ross RJ. Low relative skeletal muscle mass (sarcopenia) in older persons is associated with functional impairment and physical disability. J Am Geriatr Soc. 2002;50(5):889-96.

44. Peng T-C, Wu L-W, Chen W-L, Liaw F-Y, Chang Y-W, Kao T-W. Nonalcoholic fatty liver disease and sarcopenia in a Western population (NHANES III): the importance of sarcopenia definition. Clin Nutr. 2019;38(1):422-8.

45. Blaser MJ, Perez-Perez Gl, Kleanthous H, Cover TL, Peek RM, Chyou P, et al. Infection with Helicobacter pylori strains possessing cagA is associated with an increased risk of developing adenocarcinoma of the stomach. Can Res. 1995;55(10):2111-5.

46. Perez-Perez GI, Dworkin BM, Chodos JE, Blaser MJ. Campylobacter pylori antibodies in humans. Ann Int Med. 1988;109(1):11-7.

47. Gunter EW, Lewis BG, Koncikowski SM. Laboratory procedures used for the third National Health and Nutrition Examination Survey (NHANES III), 1988-1994. 1996.

\section{Publisher's Note}

Springer Nature remains neutral with regard to jurisdictional claims in published maps and institutional affiliations.
Ready to submit your research? Choose BMC and benefit from:

- fast, convenient online submission

- thorough peer review by experienced researchers in your field

- rapid publication on acceptance

- support for research data, including large and complex data types

- gold Open Access which fosters wider collaboration and increased citations

- maximum visibility for your research: over $100 \mathrm{M}$ website views per year

At BMC, research is always in progress.

Learn more biomedcentral.com/submissions 